\title{
O estado da arte da pesquisa sobre o fracasso escolar (1991-2002): um estudo introdutório
}

\author{
Carla Biancha Angelucci \\ Jaqueline Kalmus \\ Renata Paparelli \\ Maria Helena Souza Patto \\ Universidade de São Paulo
}

\author{
Correspondência: \\ Maria Helena Souza Patto \\ Instituto de Psicologia - USP \\ Depto PSA \\ Av. Professor Mello Moraes, 1721 \\ Caixa Postal 66261 \\ 05508-900 - São Paulo - SP \\ e-mail: mhspatto@usp.br
}

\section{Resumo}

Este artigo apresenta um estudo introdutório do estado da arte da pesquisa sobre o fracasso escolar na rede pública de ensino fundamental, partindo de uma retrospectiva histórica da pesquisa educacional no Brasil. A inserção da produção atual numa perspectiva histórica permite a percepção de continuidades e descontinuidades teórico-metodológicas, avanços e redundâncias na produção de saber sobre o objeto de estudo.

0 corpus sobre o qual incidiu a pesquisa é composto de teses e dissertações defendidas entre 1991 e 2002 na Faculdade de Educação e no Instituto de Psicologia da Universidade de São Paulo. Foram encontradas e categorizadas 71 obras, das quais treze foram analisadas em profundidade, tendo como base as seguintes questões: como o tema é abordado? Qual a concepção teórica e metodológica subjacente? Há coerência entre teoria e método? Quais as concepções de escola e de fracasso escolar que fundamentam o trabalho? Quais as relações com o conhecimento já produzido? Que novos aspectos são anunciados?

Revelaram-se vertentes que compreendem o fracasso escolar das seguintes formas: como problema essencialmente psíquico; como problema meramente técnico; como questão institucional; como questão fundamentalmente política. Verificou-se a existência de continuidades e rupturas teórico-metodológicas em relação aos caminhos percorridos pela produção de saber na área: há teses em que permanece o predomínio de concepções psicologizantes e tecnicistas de fracasso escolar; em outras, coexistem concepções inconciliáveis que resultam em um discurso fraturado; há também teses que dialogam e avançam a pesquisa crítica do fracasso escolar, inserindo-o nas relações de poder existentes numa sociedade de classes.

\section{Palavras-chave:}

Fracasso escolar - Revisão de literatura - Pesquisa educacional - Psicologia escolar. 


\title{
The state of the art in the research on school failure (1991-2002): an introductory study
}

\author{
Carla Biancha Angelucci \\ Jaqueline Kalmus \\ Renata Paparelli \\ Maria Helena Souza Patto \\ Universidade de São Paulo
}

Contact:

Maria Helena Souza Patto Instituto de Psicologia - USP Depto PSA

Av. Professor Mello Moraes, 1721 Caixa Postal 66261

05508-900 - São Paulo - SP

e-mail: mhspatto@usp.br

\begin{abstract}
Considering the political and economical changes that took place in the Brazilian society during the last decade of the 20th century, characterized as they were, among other facts, by the rising of the neoliberal ideology and by changes in the productive sector, apart from the professed emphasis government and business sectors have placed on the necessary reform of the education system aimed at achieving a competitive economy, the objective of this article is to investigate the role industrial businessmen assign to professional education within their projects of economic development. The primary reference material used were technical documents by the Confederação Nacional da Indústria (CNI National Confederation of Industries) and by the Federação das Indústrias do Estado de São Paulo (Fiesp - Industry Federation of the State of São Paulo), and also testimonies from leaders of those institutions extracted from various Brazilian periodicals. The conclusion has been that although Brazilian businessmen have emphasized investments in basic and professional education, such emphasis seeks to adjust education in Brazil to economic interests and not to regard it as a social right to be guaranteed by the state to all citizens. The analyses and proposals for education made by businessmen evolve around principles similar to those put forward by the World Bank, which adhere strictly to the Theory of Human Capital. The text also shows that such proposals regarding economic development and educational policy have been incorporated into the Brazilian central government agenda during the 1990s.
\end{abstract}

\section{Keywords}

School failure - Literature review - Educational research - School psychology. 
A importância de balanços periódicos do estado de coisas vigente numa área de pesquisa é múltipla. Eles podem detectar teoria e método dominantes; pôr em relevo aspectos do objeto de estudo que se esboçam nas entrelinhas das novas pesquisas; revelar em que medida a pesquisa recente relaciona-se com a anterior e vai tecendo uma trama que permita avançar na compreensão do objeto de estudo pela via do real acréscimo ao que já se conhece ou da superação de concepções anteriores. Só assim se podem avaliar as continuidades e descontinuidades teóricas e metodológicas e o quanto esta história se faz por repetição ou ruptura - noutras palavras, o quanto ela redunda ou avança na produção de saber sobre o objeto de estudo. Nesse tecido, sempre em formação, reside a possibilidade de evitar a cristalização do conhecimento e de fazer da pesquisa espaço de produção de saber, que tem como essência o constante movimento.

A produção de conhecimento sobre o que se convencionou chamar "fracasso escolar” tem uma longa história. Um estudo da situação atual da pesquisa desse tema não pode desconsiderar levantamentos anteriores. Para se conhecer os termos dessa continuação, é preciso situar a produção recente nas linhas e tendências apontadas por levantamentos anteriores, mesmo que difiram quanto às fontes. Daí o resumo, a seguir, das principais conclusões de estudos do estado da arte realizados em periodos anteriores.

\section{A pesquisa educacional no Brasil: breve histórico}

\section{Origens da pesquisa educacional}

Em 1971, Aparecida Joly Gouveia publicou análise extensa da pesquisa produzida no período 1965-1970 (Gouveia, 1971). Nesse relatório, a pesquisadora já ressaltava que só se poderia apreender o significado da produção naquele período se ela fosse entendida em suas relações com a produção anterior. Por isso, o artigo traz um resumo das origens da pesquisa educacional brasileira, sem o qual era impossivel entender o sentido da pesquisa não só no momento estudado pela autora, mas também nos que lhe são posteriores, até a atualidade. Nesse esboço, dois períodos: 1940-1955; 1956-1964.

Como marco inaugural, o fato de que a pesquisa educacional teve início no interior de órgãos governamentais. Os anos 1940-1955 começam com o reconhecimento oficial da importância da pesquisa na condução da política educacional. Em 1938, criou-se o Instituto Nacional de Estudos Pedagógicos (lnep) no Ministério de Educação e Cultura. Por isso, a relação entre a pesquisa e a política de educação foi primeiramente entendida em termos rigidamente instrumentais: cabia aos pesquisadores trazer subsídios práticos à formulação e avaliação de ações oficiais no campo da educação escolar.

Como característica desse momento inaugural, a presença forte da leitura psicológica do processo de educação escolar e, conseqüentemente, de estudos da psicologia do ensino e da aprendizagem e a criação de instrumentos de avaliação psicológica e pedagógica do aprendiz. Estava-se no auge da influência da Escola Nova, que assentava as bases da pedagogia científica na biologia e na psicologia. Não por acaso, a estrutura inicial do Inep incluiu uma Divisão de Psicologia Aplicada por influência do educador escolanovista e psicólogo Lourenço Filho, seu primeiro diretor. 0 primado da psicologia no entendimento do fracasso escolar é, portanto, marca de origem da pesquisa educacional.

A criação em 1956 do Centro Brasileiro de Pesquisa Educacional e de cinco centros regionais inaugura o segundo período. Novamente, a pesquisa como meio privilegiado para atingir fins governamentais. No interior da ideologia nacional-desenvolvimentista, muda, no entanto, o objeto: agora se trata de mapear a sociedade brasileira de modo a fornecer dados a uma política educacional que alavancasse 
o progresso econômico do país, levando em conta as diferenças regionais. Na pauta dos órgãos de pesquisa, a estratificação socioeconômica da população; a mobilidade social; os processos de socialização regionais e comunitários; a correlação entre escolaridade e nível socioeconômico; a composição socioeconômica da população escolar. Era a vez das ciências sociais, em chave teórica funcionalista.

No período estudado por Gouveia (1965-1970),

esboça-se a predominância de estudos de natureza econômica, incentivados não só por certos organismos prestigiosos da administração federal, mas também por fontes externas de financiamento. A educação como investimento, os custos da educação, a escola e a demanda de profissionais de diferentes níveis e outros tópicos que sugerem, igualmente, racionalização, são itens freqüentes em documentos programáticos. Como se depreende do levantamento das pesquisas em andamento, por nós aqui intentado, têm-se mostrado, nos últimos tempos, particularmente atraentes a órgãos oficiais de diferentes níveis os chamados estudos sobre recursos humanos. (1971, p. 4)

Eram tempos de predomínio da teoria do capital humano, da educação concebida como terceiro fator, até então despercebido, de desenvolvimento econômico, além do capital e do trabalho. 0 aumento quantitativo e qualitativo da educação passa a ser considerado investimento rentável. Eram tempos de ditadura militar e do desígnio oficial de pôr o país no rumo do "ordem e progresso" nos termos comteanos de desenvolvimento técnico-científico conduzido por um Estado autoritário.

A educação passou a ser assunto exclusivamente técnico. Dominam soluções tecnicistas para os problemas do ensino, tendo em vista garantir rapidez e eficiência à escolarização de parte maior da população, na proporção dos interesses da internacionalização do mercado interno. Daí o prestígio dos testes psicológicos e pedagógicos; das máquinas de ensinar e da instrução programada; das taxonomias dos objetivos do ensino; do condicionamento operante na escola; do planejamento do ensino em termos de input (competências e habilidades iniciais do aprendiz); processamento (o ensino) e output (os objetivos a serem atingidos), tudo isso detalhado em Guias Curriculares que, elaboradas nos órgãos centrais, chegavam às escolas como roteiro a ser cumprido. Nesse contexto, o fracasso escolar resultava principalmente de um processamento (ensino) que desconsiderava a precariedade do input da clientela pobre, em número crescente nos bancos escolares.

Do ponto de vista da metodologia, predominaram nos institutos oficiais estudos exploratórios e descritivos, muitas vezes simples levantamentos de estatísticas escolares. Foram muitos os surveys ou caracterizações socioeconômicas de professores e alunos da rede pública de ensino fundamental e médio e as descrições da estrutura e funcionamento de unidades escolares. Quanto aos aspectos investigados, além da caracterização de professores, alunos e escolas, estudos descritivos de métodos de ensino e recursos didáticos. Eram raras, segundo Gouveia, as pesquisas dedicadas à avaliação de inovações educacionais; inexistiam estudos da dinâmica interna das escolas e da organização e funcionamento do sistema de ensino em seus aspectos administrativos e políticos. A pesquisadora atribuía essa ausência à "falta de atenção" ou ao fato de que esses aspectos "não se têm prestado aos tipos de análise que o equipamento teórico e metodológico dos pesquisadores brasileiros permite realizar" (op. cit., p. 8). Ficamos com a segunda hipótese, até porque pensamos que a "falta de atenção" resulta de escolhas teóricas.

Nas universidades, ela encontrou quadro semelhante, exceção feita a psicólogos que, inspirados em literatura especializada norteamericana, elaboravam e adaptavam instrumentos de avaliação de capacidades e habilidades psíquicas e realizavam pesquisas que correlacionavam níveis de desenvolvimento psicoló- 
gico e rendimento escolar, sobretudo em leitura e escrita. Era nesse recorte psicológico que se elaboravam as versões dominantes sobre as causas do fracasso escolar.

Mas o locus da pesquisa educacional não era, nesse período, a Universidade:

a maior parte, porém dos trabalhos realizados por professores universitários resulta de esforços individuais relacionados com interesses intelectuais ou acadêmicos. A pesquisa é praticamente negligenciada nos orçamentos das universidades e, em geral, desempenha papel secundário na carreira do professor universitário. (Gouveia, 1971, p. 10)

Nessa mesma direção, a educação ainda não era, segundo Gouveia, área de pesquisa em agências de fomento à pesquisa, como o $\mathrm{CNPq}$ e a Fapesp.

Nesse periodo, Gouveia detectou um divórcio crescente entre pesquisa e política educacional:

considerando a situação atual, poderíamos dizer, sem exagero, que tanto a formulação da política educacional, quanto à configuração das rotinas escolares se fazem à revelia do que acontece nas instituições de pesquisa, bem como de resultados acaso obtidos por pesquisadores isolados. (...) Parece-nos igualmente legítimo afirmar que, em administrações passadas, a intenção de utilizar a pesquisa como fonte de esclarecimento para a ação traduzia-se em laços mais estreitos e iniciativas mais concretas que os existentes nestes dias. (1971, p. 17)

Nesta última situação, ela via vantagens e desvantagens. De um lado, havia maior organicidade entre pesquisa e ação educacional; de outro, havia sujeição da pesquisa a objetivos meramente pragmáticos. Por isso, ela conclui:

seriam necessários centros de estudos que tivessem certa autonomia e fossem menos atingidos pelas oscilações do arbítrio governamental. Talvez tais centros não devessem situar-se no $\mathrm{Mi}$ nistério da Educação ou do Planejamento. A universidade poderia constituir uma alternativa. (p. 19)

Por isso, encarecia a necessidade de “trazer para a educação a colaboração de pesquisadores de outros ramos das ciências humanas, programas de pesquisa de que participassem professores e alunos de pós-graduação" (p. 19).

\section{Pesquisa educacional nos anos 1970}

No período 1970-1975, Gouveia encontra um quadro diferente, não do ponto de vista teórico-metodológico, que continua positivista-experimental, mas no âmbito temático (Gouveia, 1976). Nos resumos dos congressos da Sociedade Brasileira para o Progresso da Ciência (SBPC), aumenta a presença das ciências humanas no campo da pesquisa educacional, sobretudo da psicologia. No Inep cresce, entre os projetos financiados, a pesquisa sobre elaboração de currículos e avaliação de cursos ou programas em função do mercado de trabalho, tendo em vista o planejamento curricular em estreita relação com as necessidades de mãode-obra. Mas é de novo nos Cadernos de Pesquisa que ela encontra relatos que lhe permitem fazer um retrato da pesquisa educacional na primeira metade da década de 1970 .

Os objetos mais freqüentes delimitam três categorias: avaliação de currículos e programas; construção de instrumentos de avaliação e pesquisa; características de estudantes ou do ambiente de que provêm, tendo em vista contribuir para a solução dos problemas sociais decorrentes do crescimento das matrículas nos centros urbanos. Na terceira categoria, a pesquisadora constata a predominância de estudos que não só caracterizam psicológica e sociologicamente os sujeitos ou o ambiente em que vivem, mas também investigam a influência dessas características - como variáveis 
independentes - sobre a aprendizagem ou o nível de escolaridade. Em relação aos estudos de avaliação psicológica dos alunos, que marcaram a primeira metade dessa década, a novidade é a disseminação de uma concepção de fracasso escolar e de saídas preventivas e remediativas para as altas taxas de reprovação e evasão na rede pública de ensino fundamental. Foram tempos de chegada no Brasil da "teoria" norte-americana da carência cultural.

Gouveia lamenta a presença inexpressiva, nesse período, de estudos da escola como organização social e dos sistemas administrativos em que as escolas se inserem, da política educacional e dos sistemas político-administrativos federais, estaduais e municipais nos quais se originam as decisões e se disciplinam os procedimentos que regem o cotidiano nas escolas brasileiras.

Levantamento realizado no Instituto Universitário de Pesquisas do Rio de Janeiro (luperj), que incluiu a segunda metade dos anos 1970 (1971-1981), revelou avanços em relação à situação encontrada por Gouveia até 1975 (Brandão; Baeta; Rocha, 1983). Se, por um lado, confirmam-se achados dessa pesquisadora na primeira metade da década de 1970 - principalmente a continuação da busca de deter-minantes do baixo rendimento escolar em variáveis externas ao sistema escolar, como as condições socioeconômicas e psicológicas dos usuários da escola pública por outro, objetos de estudo incipientes ou ausentes na pesquisa anterior começam a tomar forma.

Surgem pesquisas que vão além do âmbito da formação técnica do magistério como causa das dificuldades de aprendizagem e contemplam a representação docente, seja de seu trabalho, seja de seus alunos, no interior do conceito de profecia auto-realizadora. Começam a ser considerados fatores até então não levados em conta na reflexão sobre a qualidade da escola e a produção do fracasso escolar, como as condições salariais do magistério.
A novidade maior na segunda metade daquela década ficou por conta de pesquisas qualitativas voltadas para o interior da instituição escolar: a burocratização e sua influência sobre a qualidade do trabalho docente; a distância entre a cultura escolar e a cultura popular nos termos do pressuposto da carência cultural; a inadequação do material didático; a discriminação das diferenças no interior das escolas, sobretudo nas classes especiais.

Mesmo assim, tratava-se de um campo cindido: enquanto alguns estudos enfatizavam a estimulação cognitiva das crianças pobres em idade pré-escolar como estratégia preventiva de dificuldades de aprendizagem, outros começavam a destacar aspectos da estrutura e do funcionamento institucionais, suas repercussões nas práticas docentes e, por esta via, no rendimento escolar dos alunos. Mas a maioria das pesquisas que levavam em conta as chamadas variáveis intra-escolares estava centrada num aspecto da tese da carência cultural: a escola é inadequada às características psíquicas e culturais da criança carente. 0 que se destacava, portanto, era o desencontro entre professores e alunos, entre a escola e seus usuários, sem que ficasse nítido que esse desencontro é inerente à escola como instituição social que reproduz a lógica de uma sociedade dividida em classes. Por isso, continuou o predomínio de prescrições técnicas para a democratização da escola. Os tempos ainda eram de ditadura e da crença na redenção do país pelo desenvolvimento técnico e pela manutenção da ordem.

Vale perguntar se essa divisão da pesquisa em aspectos relativos ao aluno e aspectos relativos à escola já não refletia, nessa época, a duplicidade teórica que começou a se instalar nos meios em que se pensava e pesquisava a educação escolar, a partir da chegada, em 1974, de ldeologia e aparelhos ideológicos do Estado, de Louis Althusser, verdadeiro divisor de águas. A partir de então firmou-se a concepção de Escola como instituição social que só pode ser entendida se remetida à estrutura da sociedade que a inclui. 


\section{Os anos 1980: ruptura e repetição}

Na década de 1980, essa divisão se delimita e aprofunda: há ruptura e repetição temática e teórica no campo da pesquisa educacional (Patto, 1991). Se, de um lado, constata-se que, no interior da tese da carência cultural, a psicologização do fracasso escolar tem continuidade em publicações como a Revista Brasileira de Estudos Pedagógicos (Inep), de outro, o lugar social contraditório da escola numa sociedade de classes firma-se como objeto de reflexão e pesquisa. A discriminação e a justificação das desigualdades aparecem então como a razão de ser do sistema escolar. $\grave{A}$ atenção de cunho funcionalista aos fatores intra-escolares, já presente nos anos 1970, acrescentou-se a investigação da vida escolar em outro marco teórico.

Teorias críticas passaram a fazer parte das referências bibliográficas de ensaios e pesquisas sobre a escolarização e seus tropeços, principalmente as de Althusser, Bourdieu e Gramsci. 0 "fracasso escolar" foi ressignificado: de fracasso dos alunos na escola ele passa à produção da escola. No marco teórico do funcionalismo, como produto reversível, já que resultado de desacertos operacionais do sistema educacional. No marco materialista histórico ou de outras teorias críticas de sociedade, como produto inevitável da escola numa sociedade dividida.

No marco dessa rotação do olhar, um conjunto de pesquisas realizadas na Fundação Carlos Chagas caminhou na contra-mão da medicalização do fracasso escolar e voltou-se à investigação da participação do sistema escolar no baixo rendimento das crianças, em busca de mecanismos escolares de seletividade social, privilegiando o exame de aspectos estruturais e funcionais da escola e dos órgãos que a planejam. Tal abordagem resultou, na própria Fundação e fora dela, em estudos mais claramente voltados para a investigação das relações de classe e dos pressupostos da cultura dominante no interior das práticas e relações que estruturam a vida escolar e produzem dificuldades de escolarização.

Mas essa superação não se generalizou; lado a lado com estudos da realidade escolar a partir do materialismo histórico, três tendências se configuraram: continuaram as tentativas de encontrar as causas das dificuldades de aprendizagem e de ajustamento escolar no desenvolvimento psíquico do aprendiz; num mesmo relato de pesquisa a política educacional antidemocrática e o aprendiz eram simultaneamente responsabilizados pelos maus resultados do ensino, o que configurava um "discurso fraturado"; concepções críticas e não-críticas da escola na estrutura econômico-social capitalista passaram a conviver num mesmo projeto, o que indicava apropriação superficial da nova referência teórica.

A situação não era diferente no campo da sociologia da educação:

a pesquisa empirica não tem permanecido insensivel às mudanças ocorridas no discurso acadêmico sobre Educação. Não apenas se verifica a substituição de conceitos funcionalistas por outros tomados do marxismo como também a própria maneira de identificar os problemas de investigação tem se alterado. (...) As dificuldades de aplicação de formulações marxistas em pesquisas empíricas, particularmente quando se trata de pesquisa de âmbito restrito, manifestam-se claramente em alguns trabalhos de mestrado e de doutoramento. Após elaborado referencial teórico a partir do qual se anuncia a intenção de utilizar o método dialético, desenvolve-se um tipo de análise que, a não ser pelo emprego de conceitos tomados ao marxismo, não difere, na verdade, do modelo relegado sob a pecha de neo-positivista ou empiricista, predominante em épocas anteriores. (Gouveia, 1985, p. 65)

No fim dos anos 1980, a pesquisa educacional tentava superar o hiato entre conceitos macroestruturais marxistas e necessidades conceituais trazidas pelo estudo da vida esco- 
lar em sua complexidade. Na relação entre história e vida cotidiana, tal como entendida na teoria neomarxista de Agnes Heller, configurava-se uma saída. Por influência de pesquisadoras mexicanas do Centro de Investigación y de Estudios Avanzados que fizeram convergir esse referencial teórico e procedimentos de pesquisa etnográficos, pesquisadores da escola começaram a procurar acuidade conceitual para chegar ao tecido da cotidianidade escolar em busca das formas como nela seus agentes fazem a história da educação e são feitos por ela no bojo de uma sociedade de classes profundamente desigual.

\section{O estado da arte da pesquisa sobre o fracasso escolar na Universidade de São Paulo (1991-2002)}

A pesquisa e a reflexão sobre questões atinentes à escola têm sido feitas na cidade de São Paulo em dois nichos principais: de um lado, junto aos cursos de pedagogia e psicologia de universidades públicas e privadas; de outro, em fundações voltadas para a pesquisa educacional. No primeiro caso, programas de pós-graduação, com destaque para a Universidade de São Paulo e a Pontifícia Universidade Católica de São Paulo, vêm se tornando lugares significativos de produção de conhecimento sobre as grandezas e misérias do ensino brasileiro; no segundo, a Fundação Carlos Chagas destaca-se como condutora de amplos projetos de investigação no campo da educação escolar que, sem dúvida, contribuíram na definição dos rumos tomados pela pesquisa educacional nas últimas três décadas.

0 corpus sobre o qual incide esse estudo introdutório limita-se a dissertações e teses defendidas entre 1991 e 2002 na Faculdade de Educação e no Instituto de Psicologia da Universidade de São Paulo e incluídas no Dedalus (catálogo on-line do Banco de Dados Bibliográficos da USP) até julho de 2003. Trata-se, portanto, de uma primeira parte de um estudo maior, que deverá incluir outras instituições dedicadas à pesquisa educacional na cidade de São Paulo.

O levantamento teve início com um rol de expressões de busca ampliado no decorrer do próprio processo de localização dos textos referentes ao fracasso escolar. 'Procedeu-se, então, à leitura dos títulos e resumos, incluídos no Dedalus, das teses resultantes desse primeiro levantamento e realizou-se uma primeira seleção das que tinham o fracasso escolar como objeto de estudo. Foram selecionadas, nessa fase, as que o tinham como objeto explícito, mesmo que a expressão não fosse empregada para nomeá-lo. Nos casos em que o resumo disponível no catálogo não era suficiente, procedeu-se à consulta aos textos duvidosos no acervo das bibliotecas. Ao final, foram localizadas 71 obras, ${ }^{2}$ das quais 32 doutorados e 39 mestrados. ${ }^{3}$

\section{Os temas}

A análise dos resumos proporcionou uma primeira categorização das pesquisas, tendo como base o tema abordado. Foram construídas dez categorias temáticas amplas, desdobradas em

1. São elas: escola e/ou educ? e/ou aprend? associados às palavras com asterisco (*); alfabetização; analfabet?; aprend?; avaliação $\left(^{*}\right)$; carência cultural; cognição; construtivismo (*); cultura escolar; deficiência; déficit $\left(^{\star}\right)$; dificuldade(s) (*); distúrbio(s) associado a aprend? ou comportamento; ensino de primeiro grau; escrita; etnografia $\left(^{*}\right)$; evasão; exclusão $\left(^{*}\right)$; formação docente/professores; fracasso escolar; inclusão; indisciplina; instituição (*); leitura; pobreza (*); política educacional; processos cognitivos; psicanálise (*); psicodiagnóstico (*); psicopedagogia; reforma (*); relação professor-aluno; relações escolares; rendimento escolar; repetência; reprovação; sucesso escola?; transtorno(s) associado a comportamento ou aprend?; violência (*). Foram incluídas no levantamento obras que versam sobre "deficientes mentais leves" e sobre a temática da inclusão e foram excluídas aquelas cujo objeto de estudo são os portadores de síndromes e de deficiências mentais consideradas graves. Essa escolha deu-se em função do foco tradicionalmente presente no estudo do tema do fracasso escolar no Brasil: o problemático processo de escolarização da maioria dos alunos dos segmentos pobres das classes populares - que não portam deficiências mentais consideradas graves ou síndromes. Além disso, o estudo desses últimos traz especificidades que não abordaremos neste artigo.

2. As referências completas das obras encontram-se ao final, em Obras Analisadas.

3.Dezesseis teses e doze dissertações no acervo da Faculdade de Educação e dezesseis teses e 27 dissertações no Instituto de Psicologia, sob a orientação de 22 docentes em cada instituição. 
Tabela 1: Categorização das pesquisas a partir dos temas abordados

\begin{tabular}{|l|c|c|c|}
\hline \multicolumn{1}{|c|}{ Categoria } & Feusp & Ipusp & Total \\
\hline Distúrbios de desenvolvimento e problemas de aprendizagem & 01 & 11 & $\mathbf{1 2}$ \\
\hline Psicodiagnóstico de alunos com problemas de aprendizagem & 01 & 05 & $\mathbf{0 6}$ \\
\hline $\begin{array}{l}\text { Compreensão dos problemas de aprendizagem a partir } \\
\text { da teoria psicanalítica }\end{array}$ & 02 & 02 & $\mathbf{0 4}$ \\
\hline Prevenção do fracasso escolar & & 04 & $\mathbf{0 6}$ \\
\hline Remediação do fracasso escolar & 02 & 07 & $\mathbf{1 1}$ \\
\hline Papel do professor na eliminação do fracasso escolar & 04 & 05 & $\mathbf{1 0}$ \\
\hline Crítica à psicologização do fracasso escolar & 05 & 07 & $\mathbf{0 8}$ \\
\hline Fracasso escolar e trabalho dos profissionais da escola & 01 & 08 & $\mathbf{1 7}$ \\
\hline Fracasso escolar e políticas educacionais & 09 & 07 & $\mathbf{1 4}$ \\
\hline Fracasso escolar e cotidiano escolar & 07 & 05 & $\mathbf{0 5}$ \\
\hline
\end{tabular}

Área de Educação Rural - 1981/1998 - Dissertações e Teses - Banco de Dados da ANPED, 1999.

subcategorias de acordo com o objeto específico estudado pelo autor. ${ }^{5}$

Essa categorização possibilitou o levantamento de alguns aspectos preliminares, reveladores dos caminhos que a pesquisa vem percorrendo na última década. Chamou a atenção a presença significativa de pesquisas que concebem o fracasso escolar como fenômeno estritamente individual, o que pode ser observado pelo grande número de obras que constam das categorias "Distúrbios de desenvolvimento e problemas de aprendizagem", "Remediação do fracasso escolar" e "Papel do professor na eliminação do fracasso escolar". A primeira centra no aluno a responsabilidade pelo fracasso, atribuindo-lhe, predominantemente, problemas cognitivos, psicomotores ou neurológicos. Já as duas outras categorias responsabilizam ora o aluno ora o professor e propõem soluções predominantemente técnicas, de base teórica comportamental ou cognitivista, para eliminar o fracasso.

Como era de se esperar, as pesquisas constitutivas das três primeiras categorias da Tabela 1 concentram-se no lugar acadêmico em que se produz e pratica psicologia. Da mesma forma, a crítica à psicologizacão do fracasso escolar ocorre nesse mesmo lugar.

Assim como a atribuição de responsabilidade ao professor é freqüente nas pesquisas que relacionam fracasso escolar e incapacidade técnica, o trabalho docente também é alvo das pesquisas que inserem o fracasso escolar na lógica excludente da escola pública fundamental. No entanto, essas pesquisas, ancoradas numa perspectiva crítica da relação escola-sociedade, partem do princípio de que, para entender o trabalho docente, é preciso considerar o lugar da escola em uma sociedade de classes.

Ainda com base na categorização apresentada, observa-se que catorze teses procuram discutir o fracasso escolar em suas relações com as políticas educacionais, bem como com a macropolítica: trata-se de pesquisas que procuram realizar uma análise do capitalismo - ou, mais especificamente, do neoliberalismo - em suas implicações na produção do fracasso escolar.

\section{Concepções de fracasso escolar}

A leitura na íntegra de uma amostra do total de relatos levantados possibilitou uma análise mais aprofundada da pesquisa recente sobre o fracasso escolar. ${ }^{6}$ A leitura inicial e a análise foram norteadas pelas seguintes questões: qual o objeto do trabalho? Qual a teoria que o fundamenta? Qual o método de pesquisa adotado? Há coerência entre teoria e méto-

4. Para a apresentação detalhada das categorias e subcategorias, incluindo o número de obras classificadas em cada uma delas, vide Anexo.

5. Algumas obras foram listadas em mais de uma categoria.

6. A amostragem obedeceu aos seguintes critérios: garantiu-se a leitura de ao menos uma obra de cada categoria; o número de obras analisadas respeitou a proporção de referências em cada uma das categorias; foram escolhidas para análise obras contidas nas subcategorias mais numerosas. Foram analisadas ao todo treze obras, sendo oito do IP e cinco da FE, mantendo-se a proporção da produção das duas instituições. 
do? Quais as concepções de Escola e de fracasso escolar subjacentes à pesquisa? Quais as relações da pesquisa analisada com o conhecimento já produzido? Que novos aspectos do tema são abordados ou anunciados nas linhas e entrelinhas dessas pesquisas?

No cerne dessas perguntas, duas questões fundamentais: quais as teorias, métodos e concepções de fracasso escolar predominantes? A resposta pode revelar a maneira pela qual o objeto da pesquisa é compreendido e estudado.

a) O fracasso escolar como problema psíquico: a culpabilização das crianças e de seus pais

Uma das vertentes da pesquisa recente parte do princípio de que o fracasso escolar se deve a prejuizos da capacidade intelectual dos alunos, decorrentes de "problemas emocionais”. Entende-se que a criança é portadora de uma organização psíquica imatura, que resulta em ansiedade, dificuldade de atenção, dependência, agressividade, etc., que causam, por sua vez, problemas psicomotores e inibição intelectual que prejudicam a aprendizagem escolar. Não se trata da tese tradicional de que as crianças das classes populares têm rendimento intelectual baixo por carência cultural, mas de afirmar uma inibição intelectual causada por dificuldades emocionais adquiridas em relações familiares patologizantes.

Nesses trabalhos pode haver menção à implicação da escola no fracasso escolar, mas, por uma questão de "recorte de pesquisa", ela não é levada em conta. Esta decisão revela a compreensão que neles se tem de fracasso escolar: como um fenômeno que pode ser estudado sem que se considere a existência concreta da escola. As dimensões nomeadas nesses textos como "culturais", "sociais" e "econômicas” não se articulam com a dimensão "interna" ou subjetiva, que pode ser analisada isoladamente, por suposto sem qualquer prejuízo para as conclusões da pesquisa. Sob o argumento da necessidade de "recorte", isola- se o aluno que "não aprende" da escola que o ensina.

A escola pode também comparecer reduzida à relação professor-aluno; nesses casos, atitudes dos professores ou técnicas de ensino por eles utilizadas são a causa principal das dificuldades de aprendizagem. Nessas teses, pode-se afirmar que o fracasso escolar tem relação com fatores de ordem "política e social”, mas ao mesmo tempo negar que estes estejam presentes na "cultura da organização educacional”. Desse modo, as explicações centradas na tese da carência cultural acabam sendo a reposta: a pobreza dos alunos (como fator exterior à escola) é a principal causa do seu insucesso escolar.

Predomina uma concepção de escola como lugar harmônico em que o potencial de cada um encontra condições ideais para se desenvolver. A tarefa da criança, nesse contexto, é desenvolver suas capacidades egóicas para lidar com uma realidade inquestionável. É a partir dessa concepção que alguns pesquisadores estabelecem uma relação direta entre desempenho escolar e saúde mental. Cabe ao aluno adaptar-se, com a contribuição de professores e psicólogos. No interior de uma concepção de normalidade como adaptação, o não ajustamento à escola ou a insatisfação com características do ambiente escolar são incapacidade individual de orientar-se pelo princípio de realidade.

Entre as pesquisas que atribuem o fracasso escolar a problemas emocionais individuais, há uma forte presença do emprego de grupos controle e experimental. É interessante ressaltar que elas chegam a resultados inconciliáveis. Em uma delas, os membros dos grupos controle e experimental obtêm um bom rendimento nas avaliações intelectuais, mas as avaliações de personalidade indicam problemas de natureza emocional; o que diferencia o grupo experimental, portador de queixa escolar, é o não acolhimento de suas angústias pelos pais e a conseqüente inibição intelectual. Em outra, tanto o grupo experimental quanto o grupo 
controle apresentaram baixo desempenho intelectual; assim sendo, o que explica o sucesso escolar dos integrantes do segundo grupo é o fato de eles terem maturidade emocional suficiente para lidar com dificuldades escolares resultantes do baixo nível de inteligência. Sem diálogo entre elas (uma das pesquisas foi defendida em 1993 e a outra em 1998), fica a seguinte questão: até que ponto os resultados de uma pesquisa são entendidos de modo a confirmar as hipóteses do pesquisador?

Nessa modalidade de pesquisa, a revisão bibliográfica por vezes assume caráter meramente burocrático, e se limita a listar o maior número possível de pesquisas realizadas sobre o tema, sem atenção às diferenças de concepções, procedimentos e resultados encontrados, como se fossem equivalentes. Dessa forma, o avanço do conhecimento sobre o objeto de estudo fica seriamente comprometido.

b) O fracasso escolar como um problema técnico: a culpabilização do professor

Outra perspectiva encontrada é a que concebe o fracasso escolar como efeito de técnicas de ensino inadequadas ou de falta de domínio da técnica correta pelo professor. Permanece nessas pesquisas o pressuposto de que as crianças das classes populares trazem para a escola dificuldades de aprendizagem, mas o foco muda de lugar: não se localiza nos problemas individuais dos alunos, mas na técnica de ensino do professor. Nesse sentido, leva-se em conta a escola na produção dos reveses da aprendizagem, mas reduzida a uma relação dual abstrata em uma escola abstrata, ou seja, desvinculadas da sociedade que as inclui.

Mesmo quando faz referência ao "descaso das autoridades" para com a escola pública, as teses dessa vertente continuam dentro da lógica tecnicista, pois o descaso é reduzido ao fato de as autoridades não proporcionarem formação técnica adequada aos professores. Afirma-se que o fracasso escolar é produzido na e pela escola, mas reduz-se esta produção à sua inadequação técnica. Na verdade, continua-se a compreender o fracasso escolar como resultado de variáveis individuais, embora nessas teses a variável independente investigada seja a capacidade profissional do professor.

Marcado pela tese da carência cultural, um dos relatos analisados dá continuidade à versão que marcou a pesquisa do fracasso escolar nos anos 1970: os professores estão preparados para escolarizar crianças ideais, mas não os usuários predominantes da escola pública primária - as crianças pobres.

Está presente nessa produção o pressuposto de que os alunos possuem dificuldades de ordem emocional, cultural, etc., que podem ser sanadas pelo professor se ele utilizar a técnica de ensino adequada. 0 construtivismo é a alternativa mais comumente apresentada; o professor deve dominá-lo, acreditar na capacidade de desenvolvimento da criança e atuar mediante intervenções psicopedagógicas. Por meio desses procedimentos, prevê-se o ajustamento da criança a uma escola que, baseada na técnica correta, proporcionaria condições propícias ao desenvolvimento das potencialidades dos aprendizes.

0 acento técnico dessa concepção de fracasso escolar fica patente na preocupação com a eficácia da prática pedagógica. Nesse contexto, ser bom professor significa ter formação técnica adequada; refletir sobre a prática; planejar as intervenções; estar motivado. Se todos esses critérios forem garantidos e, ainda assim, houver crianças que não aprendem, aí sim se pode afirmar a presença de dificuldades psíquicas individuais que devem ser encaminhadas a especialistas.

A partir do entendimento do fracasso escolar como resultado de técnicas de ensino inadequadas ou mal digeridas, pesquisadores se propõem a aplicar eles mesmos técnicas em grupos de crianças com queixa escolar a fim de provar a sua tese, melhorando o desempenho escolar ou, pelo menos, as respostas dadas pelos sujeitos da pesquisa no contexto experimental. Também nessas pesquisas, os casos 
que contradizem a hipótese inicial são tomados como indicativos de deficiências individuais que necessitam de acompanhamento especial, e não como resultado que problematiza a hipótese de que o simples emprego da técnica adequada é suficiente para reverter as dificuldades de escolarização.

Essas pesquisas consideram a crítica às concepções psicologizantes ou medicalizantes do fracasso escolar quando se referem à necessidade de se compreender as origens e significados da "queixa escolar", em vez de simplesmente atribuí-la a dificuldades do aluno. No entanto, acabam por voltar à redução que criticam, ao restringirem-se à avaliação $d a$ criança e à intervenção na criança.

c) O fracasso escolar como questão institucional:

a lógica excludente da educação escolar

Há pesquisas que entendem a escola como instituição social que contraditoriamente reproduz e transforma a estrutura social. Partem do princípio de que o fracasso escolar é um fenômeno presente desde o início da instituição da rede de ensino público no Brasil. A análise dos processos institucionais que levam à produção do fracasso deve considerar a escola como instituição inserida em uma sociedade de classes regida pelos interesses do capital, sendo que a própria política pública encontrase entre os determinantes do fracasso escolar. Assim, a reversão desse quadro requer, da política educacional, resistência aos interesses privatizantes e compromisso com a construção de uma escola pública capaz de distribuir com mais igualdade habilidades e conhecimentos que lhe cabe transmitir.

Ao inserirem a produção do fracasso escolar no âmbito de condições escolares objetivas, fazem do contato direto do pesquisador com a vida escolar - o que, normalmente, pressupõe uma longa permanência no campo e das relações não objetificantes entre pesquisador e pesquisados os principais instrumentos de pesquisa.
Tais princípios não impedem, entretanto, uma compreensão parcial das teorias críticas da escola nas pesquisas que as têm como referência: ao mesmo tempo em que afirmam que, para pensar a escola e seus resultados, é preciso tomá-la como instituição seletiva e excludente, retomam o tecnicismo ao admitirem a possibilidade de pôr sob controle o fracasso escolar por meio da adequada implementação de políticas educacionais "progressistas”, com especial ênfase na política de ciclos de aprendizagem. 0 insucesso de reformas e projetos nesta direção encontra explicação no conservadorismo dos professores que, pela resistência à inovação, prejudicam a sua implementação. A saída apontada é o investimento na formação intensiva dos professores, de modo a levá-los a conhecer em profundidade as propostas governamentais e, assim, garantir a realização do objetivo final de reformas e projetos oficiais: a reversão do fracasso escolar.

Essas pesquisas podem diferir também quanto à definição dos responsáveis pela reformulação da política educacional. Há pesquisadores que pressupõem a construção coletiva dessa política, com a participação de educadores e movimentos sociais, até o limite do possível nas condições históricas atuais; outros entendem que, para garantir a formação intelectual das classes populares, essa política deve ser elaborada por especialistas e informada por teorias de desenvolvimento, da aprendizagem e do ensino - entre os autores citados, destacam-se Piaget e Vygotsky. Ao defenderem essa posição, as teses e dissertações defendem a divisão entre "planejadores" e "executores".

d) O fracasso escolar como questão política: cultura escolar, cultura popular e relações de poder

Por fim, há uma vertente que enfatiza a dimensão política da escola. Assim como as pesquisas que se debruçam sobre a lógica excludente da educação escolar, analisadas no item anterior, aqui também se compreende a 
escola como uma instituição social regida pela mesma lógica constitutiva da sociedade de classes. 0 foco, entretanto, incide nas relações de poder estabelecidas no interior da instituição escolar, mais especificamente na violência praticada pela escola ao estruturar-se com base na cultura dominante e não reconhecer - e, portanto, desvalorizar - a cultura popular.

Ao considerarem os determinantes sociopolíticos do ensino, partem da crítica às concepções tradicionais de fracasso escolar e trazem novos elementos que contribuem para a sua superação. Fazem a crítica à tese de que as crianças das classes populares são carentes de cultura ou possuem deficiências cognitivas e emocionais; à relação pedagógica concebida como processo individual; às tentativas de superação do fracasso escolar por meio de medidas técnico-pedagógicas de inclusão nos sistemas escolar e social, todos eles centrados na idéia de escola como entidade abstrata.

Essas pesquisas criticam as relações causais lineares entre "problemas individuais" e "problemas de aprendizagem" para explicar as dificuldades de escolarização dos alunos oriundos das classes populares, porque questionam a polarização entre indivíduo e sociedade e compreendem a constituição do sujeito nas condições concretas de existência num determinado lugar da hierarquia social.

Ao debruçarem-se sobre a realidade social em que se dá a escolarização das crianças pertencentes às classes subalternas, desconstroem os fenômenos nomeados pelos profissionais da escola e pelos formuladores de políticas educacionais como "não-aprendizado", "problema emocional”, "indisciplina”, “carência cultural”, etc. Essas categorias abstratas são ressignificadas e entendidas não mais como fenômeno individual, sintoma de conflitos intrapsíquicos, ou como expressão reativa da resistência a práticas escolares inadequadas, mas em sua positividade, como expressão do conflito de classes no interior da escola. Sob essa ótica, a indisciplina escolar pode ser tentativa de participação dos alunos no mundo da escola, a partir de seus próprios referenciais culturais.

Também é comum a esses trabalhos a construção de perguntas e procedimentos de pesquisa para respondê-las que querem implicar ativamente os pesquisados, ou seja, transformálos de objetos de pesquisa em sujeitos sem os quais é impossível produzir conhecimento. Há, portanto, uma ruptura epistemológica: do conhecimento sobre a "criança fracassada", o "professor incompetente", as "famílias desestruturadas" para o conhecimento que incorpora a fala dos alunos, dos profissionais da escola, das famílias das classes populares, numa proposta de resgate da legitimidade de seus saberes, experiências e percepções.

\section{Reflexões e conclusões}

Um dos aspectos pregnantes da produção examinada é a continuidade de pesquisas do fracasso escolar que o concebem em chave psicologizante. A permanência desta versão, apesar de já superada pela crítica que desvela as lacunas ou silêncios de que ela é feita, pode nos revelar: a) a força da redução psicológica na explicação do insucesso escolar que, ao passar por sucessivos "renascimentos", mostra o poder de convencimento que têm as concepções que não vão além do senso comum; b) a compartimentalização do campo teórico, reforçada pela crença de que as ciências humanas se caracterizam por diversidade teórica benéfica que deve ser preservada; c) a recusa da crítica teórica, vista com maus olhos (porque entendida como implicância ou confusão equivocada ou mal-intencionada entre ciência e política), ou simplesmente ignorada, porque relativizada.

Como resultado, um campo de produção de conhecimento que não caminha por meio da superação de concepções examinadas em suas raízes epistemológicas e ético-políticas, mas de acréscimos estanques, que não fazem o conhecimento avançar.

Em outra vertente, que dá continuidade à linha de pesquisa de base materialista 
histórica do fracasso escolar iniciada nos anos 1980, teses discutem o caráter ideológico de concepções do fracasso escolar, que retiram a escola e as práticas que nela se dão de seu contexto econômico e político, e põem em questão o caráter neutro ou desinteressado da ciência.

A partir da reinterpretação da política educacional no interior das relações de poder numa sociedade de classes extremamente desigual, dimensões escolares ganham novos significados. Reformas e projetos recentes são entendidos no marco do barateamento da educação pública no bojo do neoliberalismo e da globalização. Investigam-se as conseqüências lesivas dessas políticas sobre as condições de trabalho dos educadores. Ouvem-se alunos que passaram por "classes de aceleração", professores imersos na política de inclusão, famílias cujos filhos estão em séries avançadas da escola básica, sem terem sido alfabetizados.

De outro lado, questionam-se crenças incrustadas no cotidiano escolar, como a de que a inserção precoce no mercado de trabalho é causa de fracasso escolar, e a alardeada "democratização da escola” pela simples passagem dos excluídos do direito à formação escolar à categoria de incluídos nos prédios escolares. Discutem-se instrumentos de avaliação psicológica, categorias diagnósticas de dificuldades de aprendizagem em seus aspectos epistemológicos e ético-políticos, aprofunda-se a discussão da relação da cultura escolar com a cultura popular e da desvalorização desta em projetos pedagógicos oficiais. Problematizam-se, enfim, as abstrações e inversões presentes na pesquisa educacional. Como afirma Azanha:

ao considerar que a relação pedagógica pode ser orientada a partir de teorias que pretendem descrever e explicar a natureza do conhecimento que o professor ensina, e a natureza da aprendizagem que o aluno desenvolve, essa idéia ganha a fisionomia de um jogo abstrato entre parceiros abstratos: o preceptor e o discípulo. Na escola contemporânea, seja ela pública ou privada, o professor individual que ensina e o aluno individual que aprende são ficções; seres tão imaginários quanto aqueles a que se referem expressões como "homo economicus", "aluno médio", "sujeito epistêmico" e outras semelhantes. (2000, p. 9)

Além da coexistência de concepções inconciliáveis que caminham em paralelo, verificamse tentativas de conciliação nem sempre bemsucedidas. Na base desse insucesso, está a deficiência de formação teórica revelada por pesquisadores da educação escolar. É assim que relatos de pesquisa podem começar com o resumo de publicações que falam do lugar da escola numa sociedade de classes e de sua expressão nas práticas pedagógicas, para imediatamente propor a avaliação de habilidades mentais dos que não conseguem se escolarizar, com o objetivo de explicar essa situação. Em tais casos, estamos diante da continuação do "discurso fraturado".

A precariedade da aprendizagem teórica pode ter outras manifestações. No corpus examinado a simplificação teórica é recorrente; a psicanálise e a epistemologia genética, por exemplo, comparecem, como regra, em suas versões "vulgares" - ou seja, simplificadas, destituídas de complexidade, trivializadas. Essa insuficiência pode também assumir a forma de desconhecimento dos nexos teoria-método. À transcrição de passagem de texto que concebe a escola como instituição social atravessada de interesses de classes em conflito, pode suceder o relato de uma pesquisa em moldes experimentais, com o objetivo de verificar a relação do fracasso escolar - definido como variável independente - com o nivel de desenvolvimento cognitivo, tomado como variável dependente.

De modo semelhante, a própria concepção de Escola como instituição social complexa numa sociedade de classes pode rapidamente reduzir-se a uma pesquisa centrada no professor não como trabalhador da educação, mas como profissional carente de conhecimentos técnicos que poderiam redimir a escola das dificuldades que enfrenta. 
A superficialidade do conhecimento de teoria e métodos manifesta-se também na confusão deste último com simples técnicas de coleta de dados. É assim que a observação; a entrevista; a etnografia; a aplicação de instrumentos de avaliação psíquica aparecem muitas vezes nomeados como "método". É assim que "pesquisa qualitativa" passa a designar qualquer procedimento que não resulte em quantificação ou tratamento estatístico de dados, sem atenção à necessidade de rigor no ato de pesquisar.

A repetição de objetos e de procedimentos de pesquisa, que chegam a conclusões já conhecidas; a dispersão temática que revela escolhas que desconsideram as questões mais prementes da problemática educacional e por isso resultam em pesquisas pouco relevantes; a falta de diálogo com pesquisas já realizadas sobre aspectos do mesmo objeto também estão presentes no conjunto de relatos analisados. Para não falar da presença, entre as teses analisadas, de uma pesquisa que, de fato, não o é: não há pergunta, não há pesquisa, não há levantamento bibliográfico, não há trabalho teórico-conceitual; há apenas uma tese inicial que é repetida com palavras diferentes no decorrer do texto.

A ausência de pesquisas baseadas em tratamento estatístico de dados entre as teses analisadas pode ter significado negativo e positivo no interior dos trabalhos. Negativo porque pode revelar compreensão equivocada do método utilizado - por exemplo, criam-se grupos experimental e de controle, controlam-se variáveis, pergunta-se pela correlação entre elas, mas não há procedimentos estatísticos de análise dos dados obtidos, o que revela entendimento equivocado tanto do modelo experimental quanto da pesquisa qualitativa.

Positivo porque são cada vez mais freqüentes pesquisas a respeito do fenômeno do fracasso escolar que, de fato qualitativas, centram-se no estudo de poucos casos, e têm como material de campo entrevistas com os vários participantes da vida escolar, nas quais eles deixam de ser objetos e passam a sujeitos que participam ativamente da produção do conhecimento que resulta da pesquisa. São pesquisas, em sua maioria, que se incluem na segunda tendência referida anteriormente, em que os pesquisadores ultrapassam a tradição da fala sobre os sujeitos da pesquisa do fracasso escolar para incluir a fala dos participantes da vida escolar, analisadas por meio de procedimentos não-quantitativos de análise de discurso.

Tudo isso fala das grandezas e misérias dos currículos de graduação e de pós-graduação. Tudo isso traz a necessidade de reflexão sobre as práticas de inserção dos pós-graduandos nas linhas de pesquisa dos programas de pós-graduação e o lugar dos orientadores na definição dos objetos de estudo de teses de mestrado e doutorado, de modo que contemplem questões relevantes levantadas, mas não respondidas, por pesquisas anteriores. Só assim, o campo da pesquisa educacional poderá ser mais do que um conjunto de pesquisas que não somam, ou somam pouco e, por isso, acabam trazendo contribuição limitada ao avanço do entendimento de questões candentes postas pela realidade escolar brasileira, de modo a colaborar, de fato, com a construção histórica da escola pública democrática. 


\section{ANEXO}

Quadro detalhado das categorias e subcategorias temáticas levantadas

Distúrbios de desenvolvimento e problemas de aprendizagem

\begin{tabular}{|l|c|c|c|}
\hline & FEUSP & IPUSP & TOTAL \\
\hline a) dificuldades cognitivas/psicomotoras & 1 & 4 & $\mathbf{5}$ \\
\hline b) dificuldades no desenvolvimento emocional & 0 & 3 & $\mathbf{3}$ \\
\hline c) dificuldades neuropsicológicas & 0 & 4 & $\mathbf{4}$ \\
\hline TOTAL & $\mathbf{1}$ & $\mathbf{1 1}$ & $\mathbf{1 2}$ \\
\hline
\end{tabular}

Psicodiagnóstico de alunos com problema de aprendizagem

\begin{tabular}{|l|c|c|c|}
\hline & FEUSP & IPUSP & TOTAL \\
\hline a) diagnóstico da deficiência mental & 1 & 1 & $\mathbf{2}$ \\
\hline $\begin{array}{l}\text { b) dinâmica intrapsiquica do aluno com fracasso } \\
\text { escolar }\end{array}$ & 0 & 3 & \\
\hline $\begin{array}{l}\text { c) reformulação do psicodiagnóstico para que se torne } \\
\text { mais eficiente para 0 aluno e para a escola }\end{array}$ & 0 & 1 & $\mathbf{3}$ \\
\hline TOTAL & $\mathbf{1}$ & $\mathbf{5}$ & $\mathbf{6}$ \\
\hline
\end{tabular}

Compreensão dos problemas de aprendizagem a partir da teoria psicanalítica

\begin{tabular}{|c|c|c|c|}
\hline & FEUSP & IPUSP & TOTAL \\
\hline $\begin{array}{l}\text { a) crítica à eficácia do psicodiagnóstico tradicional a } \\
\text { partir da psicanálise }\end{array}$ & 0 & 1 & 1 \\
\hline b) causas do fracasso escolar nas relações familiares & 0 & 1 & 1 \\
\hline $\begin{array}{l}\text { c) falhas ambientais/carência cultural causando } \\
\text { problemas emocionais que resultam em fracasso } \\
\text { escolar }\end{array}$ & 2 & 0 & 2 \\
\hline TOTAL & 2 & 2 & 4 \\
\hline
\end{tabular}

Prevenção do fracasso escolar

\begin{tabular}{|l|c|c|c|}
\hline \multicolumn{1}{|c|}{} & FEUSP & IPUSP & TOTAL \\
\hline a) através da alfabetização pelo método construtivista & 0 & 1 & $\mathbf{1}$ \\
\hline b) através da pré-escola & 0 & 1 & $\mathbf{1}$ \\
\hline $\begin{array}{l}\text { c) através do diagnóstico do processamento auditivo } \\
\text { central }\end{array}$ & 0 & 1 & \\
\hline d) através da psicopedagogia & 2 & 0 & $\mathbf{2}$ \\
\hline $\begin{array}{l}\text { e) através de procedimentos experimentais I } \\
\text { cognitivistas }\end{array}$ & 0 & 1 & $\mathbf{1}$ \\
\hline TOTAL & $\mathbf{2}$ & $\mathbf{4}$ & $\mathbf{6}$ \\
\hline
\end{tabular}

Remediação do fracasso escolar

\begin{tabular}{|l|c|c|c|}
\hline & FEUSP & IPUSP & TOTAL \\
\hline $\begin{array}{l}\text { a) através de procedimentos experimentais / } \\
\text { behavioristas }\end{array}$ & 1 & 2 & $\mathbf{3}$ \\
\hline $\begin{array}{l}\text { b) através de procedimentos baseados em teorias de } \\
\text { Piaget / Vygotsky }\end{array}$ & 1 & 3 & $\mathbf{4}$ \\
\hline c) através da relação professor-aluno & & & \\
\hline d) através da psicopedagogia & 0 & 0 & $\mathbf{1}$ \\
\hline e) através de procedimentos psicanalíticos & 0 & 1 & $\mathbf{1}$ \\
\hline $\begin{array}{l}\text { f) através do conhecimento das concepções da } \\
\text { comunidade escolar }\end{array}$ & 1 & 0 & $\mathbf{1}$ \\
\hline TOTAL & $\mathbf{4}$ & $\mathbf{7}$ & $\mathbf{1 1}$ \\
\hline
\end{tabular}


Papel do professor na eliminação do fracasso escolar

\begin{tabular}{|l|c|c|c|}
\hline & FEUSP & IPUSP & TOTAL \\
\hline a) formação docente em cursos de capacitação & 0 & 1 & $\mathbf{1}$ \\
\hline b) necessidade de domínio da técnica & 3 & 4 & $\mathbf{7}$ \\
\hline c) importância da auto-estima do professor & 1 & 0 & $\mathbf{1}$ \\
\hline d) perfil do professor competente & 1 & 0 & $\mathbf{1}$ \\
\hline TOTAL & $\mathbf{5}$ & $\mathbf{5}$ & $\mathbf{1 0}$ \\
\hline
\end{tabular}

Crítica à psicologização do fracasso escolar

\begin{tabular}{|l|c|c|c|}
\hline & FEUSP & IPUSP & TOTAL \\
\hline $\begin{array}{l}\text { a) reformular o psicodiagnóstico para não } \\
\text { discriminar/rotular o aluno }\end{array}$ & 0 & $\mathbf{1}$ \\
\hline $\begin{array}{l}\text { b) crítica ao psicodiagnóstico do aluno com história de } \\
\text { fracasso escolar }\end{array}$ & 0 & 1 & $\mathbf{1}$ \\
\hline $\begin{array}{l}\text { c) análise crítica das diferentes formas do psicólogo } \\
\text { compreender e trabalhar com o fracasso escolar }\end{array}$ & 0 & 1 & $\mathbf{1}$ \\
\hline $\begin{array}{l}\text { d) crítica ao conceito de deficiência mental leve e ao } \\
\text { seu emprego na justificação do fracasso escolar }\end{array}$ & 0 & 1 & $\mathbf{1}$ \\
\hline e) crítica à idéia de prontidão & 0 & 1 \\
\hline $\begin{array}{l}\text { f) crítica à idéia de problemas afetivos como causa dos } \\
\text { problemas de aprendizagem }\end{array}$ & 1 & $\mathbf{1}$ \\
\hline $\begin{array}{l}\text { g) crítica à teoria da carência cultural, à psicologia do } \\
\text { desenvolvimento e ao construtivismo como } \\
\text { explicações para o fracasso escolar }\end{array}$ & 0 & $\mathbf{1}$ \\
\hline TOTAL & & $\mathbf{2}$ \\
\hline
\end{tabular}

Fracasso escolar e trabalho dos profissionais da escola

\begin{tabular}{|c|c|c|c|}
\hline & FEUSP & IPUSP & TOTAL \\
\hline $\begin{array}{l}\text { a) trabalhar com os professores para que se apropriem } \\
\text { das propostas democratizantes }\end{array}$ & 1 & 0 & 1 \\
\hline $\begin{array}{l}\text { b) crítica à culpabilização do professor pelo fracasso } \\
\text { escolar }\end{array}$ & 0 & 2 & 2 \\
\hline c) análise da formação de professores e neoliberalismo & 0 & 2 & 2 \\
\hline $\begin{array}{l}\text { d) importância da relação professor-aluno para } 0 \\
\text { sucesso escolar }\end{array}$ & 3 & 1 & 4 \\
\hline $\begin{array}{l}\text { e) compreensão da relação professor-aluno como } \\
\text { relação de poder }\end{array}$ & 0 & 1 & 1 \\
\hline f) análise do caráter excludente da avaliação escolar & 2 & 1 & 3 \\
\hline g) análise do papel da direção da escola & 1 & 0 & 1 \\
\hline h) análise do professor como trabalhador & 1 & 0 & 1 \\
\hline i) o professor bem sucedido e a instituição escolar & 1 & 1 & 2 \\
\hline TOTAL & 9 & 8 & 17 \\
\hline
\end{tabular}




\begin{tabular}{|c|c|c|c|}
\hline & FEUSP & IPUSP & TOTAL \\
\hline $\begin{array}{l}\text { a) superação do fracasso através de políticas } \\
\text { compensatórias }\end{array}$ & 1 & 0 & 1 \\
\hline b) capitalismo / neoliberalismo e fracasso escolar & 0 & 3 & 3 \\
\hline c) análise das políticas de inclusão & 1 & 1 & 2 \\
\hline $\begin{array}{l}\text { d) análise das políticas de progressão continuada / } \\
\text { ciclos de aprendizagem / classes de aceleração }\end{array}$ & 2 & 2 & 4 \\
\hline e) reflexão sobre a gestão democrática da escola & 1 & 0 & 1 \\
\hline f) jovens com história de fracasso e políticas públicas & 1 & 0 & 1 \\
\hline $\begin{array}{l}\text { g) apontamento da necessidade de reformulação do } \\
\text { trabalho escolar }\end{array}$ & 1 & 1 & 2 \\
\hline TOTAL & 7 & 7 & 14 \\
\hline
\end{tabular}

Fracasso escolar e cotidiano escolar

\begin{tabular}{|c|c|c|c|}
\hline & FEUSP & IPUSP & TOTAL \\
\hline $\begin{array}{l}\text { a) prática de encaminhamento do aluno fracassado } \\
\text { para } 0 \text { trabalho }\end{array}$ & 0 & 1 & 1 \\
\hline b) análise dos significados da indisciplina escolar & 0 & 2 & 2 \\
\hline c) práticas escolares produtoras de fracasso & 0 & 2 & 2 \\
\hline TOTAL & $\mathbf{0}$ & 5 & 5 \\
\hline
\end{tabular}

\section{Referências bibliográficas}

AZANHA, M. P. Uma reflexão sobre a formação do professor da escola básica. In: CONSELHO ESTADUAL DE EDUCAÇÃO, processo CCE n.64/99, indicação CEE n.07/2000.

BRANDÃO, Z.; BAETA, A. M. B.; ROCHA, A. D. C. 0 estado da arte da pesquisa sobre evasão e repetência no ensino de $1^{\circ}$ grau no Brasil. Revista Brasileira de Estudos Pedagógicos, Brasília, v. 64, n. 147, p. 38-69, 1983.

GOUVEIA, A. J., A pesquisa educacional no Brasil. Cadernos de Pesquisa, São Paulo, n. 1, p. 1-48, 1971.

A pesquisa sobre educação no Brasil: de 1970 para cá. Cadernos de Pesquisa, São Paulo, n. 19, p. 75-79, 1976.

. Orientações teórico-metodológicas da sociologia da educação no Brasil. Cadernos de Pesquisa, São Paulo, n. 55, p. 37, 1985.

PATTO, M. H. S. A produção do fracasso escolar. histórias de submissão e rebeldia. São Paulo: T. A. Queiroz, 1991. 385 p.

\section{Obras analisadas}

\section{Feusp}

ALGARTE, R. A. Escola brasileira e lógica do fracasso: estudo sobre dissimulação e cooptação na política educacional. 1991. Tese (Doutorado)—Faculdade de Educação da Universidade de São Paulo, São Paulo, 1991.

AFFONSO, I. G. Ensino municipal: gestão e sistema. 1991. Dissertação (Mestrado)—Faculdade de Educação da Universidade de São Paulo, São Paulo, 1991.

ALAVARSE, 0. M. Ciclos: a escola em (como) questão. 2002. Dissertação (Mestrado)—Faculdade de Educação da Universidade de São Paulo, São Paulo, 2002.

ALBUQUERQUE, A. C. A. A política educacional no estado de São Paulo: a implantação de medidas para contenção de evasão e repetência no ensino fundamental (1983-1992). 2000. Dissertação (Mestrado)— Faculdade de Educação da Universidade de São Paulo, São Paulo, 2000. 
BARROS, L. À escola o que é da escola: a especificidade da escola. 2000. Dissertação (Mestrado)—Faculdade de Educação da Universidade de São Paulo, São Paulo, 2000.

BATISTA, L. P. Os jovens de periferia e a escola pública: um estudo de caso. 2002. Dissertação (Mestrado)— Faculdade de Educação da Universidade de São Paulo, São Paulo, 2002.

BOSSA, N. A. Fracasso escolar. um sintoma da contemporaneidade revelando a singularidade. 2000. Tese (Doutorado)—Faculdade de Educação da Universidade de São Paulo, São Paulo, 2000.

COSTA, M. L. G. Benefícios e entraves da inclusão escolar e social de crianças com dificuldades no processo de construção da linguagem. 2002. Tese (Doutorado)— Faculdade de Educação da Universidade de São Paulo, São Paulo, 2002.

FERREIRA, M. E. C. O enigma da inclusão: das intenções às práticas pedagógicas. 2002. Tese (Doutorado)— Faculdade de Educação da Universidade de São Paulo, São Paulo, 2002.

GARCIA, T. M. F. B. Esculpindo geodos, tecendo redes: estudo etnográfico sobre o tempo e avaliação na sala de aula. 1996. Dissertação (Mestrado)— Faculdade de Educação da Universidade de São Paulo, São Paulo, 1996.

GOULART, A. M. P. L. O professor na mediação cultural: as contribuições de Reuven Feuerstein junto a alunos com necessidades especiais. 2000. Tese (Doutorado)— Faculdade de Educação da Universidade de São Paulo, São Paulo, 2000.

ISEPI, M. Interações adulto-criança em situações de leitura: a experiência do Projeto Letras e Livros. 1999. Dissertação (Mestrado)— Faculdade de Educação da Universidade de São Paulo, São Paulo, 1999.

JACOMINI, M. A. Uma década de organização do ensino em ciclos na rede municipal de São Paulo: um olhar dos educadores. 2002. Dissertação (Mestrado) — Faculdade de Educação da Universidade de São Paulo, São Paulo, 2002.

MACIEL, D. A. Análise das interações professora-criança em situação de ensino aprendizagem da leitura e escrita. 1996. Tese (Doutorado)— Faculdade de Educação da Universidade de São Paulo, São Paulo, 1996.

MAMAN, C. F. Psicopedagogia inter-ativa: ação psicopedagógica institucional baseada em uma convergência teórica. 1997. Dissertação (Mestrado) — Faculdade de Educação da Universidade de São Paulo, São Paulo, 1997.

MANTOVANNI, M. C. L. O olhar do professor ao diagnosticar dificuldades de aprendizagem: critérios e justificativas empregados para a escolha dos bons e maus alunos. 1999. Tese (Doutorado)—Faculdade de Educação da Universidade de São Paulo, São Paulo, 1999.

MANZOLI, L. P. Classe especial: caracterizando o aluno portador de deficiência mental. 1994. Tese (Doutorado)—Faculdade de Educação da Universidade de São Paulo, São Paulo, 1994.

MATTOS, E. A. Contribuições do estudo e proposta para o processo de inclusão do aluno com necessidades educacionais especiais - deficiente mental - na escola comum. 2000. Tese (Doutorado)— Faculdade de Educação da Universidade de São Paulo, São Paulo, 2000.

MONTEIRO, S. A. I. Luzes, sombras e crepúsculos nas vivências cotidianas de duas escolas de primeiro grau: sucessos, fracassos, evasões, exclusões. 1996. Tese (Doutorado)— Faculdade de Educação da Universidade de São Paulo, São Paulo, 1996.

NASCIMENTO, R. P. Relações sociais em Cidade Tiradentes: um estudo preliminar das relações entre educação e moradia. 1998. Dissertação (Mestrado) — Faculdade de Educação da Universidade de São Paulo, São Paulo, 1998.

NEIRA, M. G. Educação física: a professora polivalente e o aluno. 2002. Tese (Doutorado)—Faculdade de Educação da Universidade de São Paulo, São Paulo, 2002.

NOFFS, N. A. Psicopedagogia institucional: a trajetória de seus atores-autores. 1996. Tese (Doutorado)—Faculdade de Educação da Universidade de São Paulo, São Paulo, 1996.

PINTO, N. B. O erro como estratégia didática no ensino de matemática elementar. 1998. Tese (Doutorado)— Faculdade de Educação da Universidade de São Paulo, São Paulo, 1998. 
SILVA, Z. A. P. M. Prática pedagógica do professor alfabetizador: o que falta e o que precisa mudar. 1992. Tese (Doutorado)— Faculdade de Educação da Universidade de São Paulo, São Paulo, 1992.

VASCONCELOS, C. S. Processo de mudança da avaliação da aprendizagem: o papel do professor, representações e práticas. 1998. Tese (Doutorado)—Faculdade de Educação da Universidade de São Paulo, São Paulo, 1998.

VIANNA, I. O. A. Administração da escola pública: um desafio pedagógico e político. 1992. Tese (Doutorado)— Faculdade de Educação da Universidade de São Paulo, São Paulo, 1992.

\section{Ipusp}

AIELLO, A.L.R. Efeitos sobre um procedimento de resposta construída sobre a rede de relações de equivalência envolvida em leitura e escrita em crianças com história de fracasso escolar. São Paulo, 1995. Tese (Doutorado)- Instituto de Psicologia da Universidade de São Paulo.

ALVES, L. A. Referenciais para formação de professores: uma análise crítica do discurso oficial sobre qualidade e competência do ponto de vista da Psicologia Escolar. São Paulo, 2002. Dissertação (Mestrado)- Instituto de Psicologia da Universidade de São Paulo.

AMBROGI, I. H. O discurso do professor alfabetizador considerado bem sucedido: uma análise de suas práticas cotidianas. 1998. Dissertação (Mestrado)- Instituto de Psicologia da Universidade de São Paulo, São Paulo, 1998.

ANACHE, A. A. Diagnóstico ou inquisição?: estudo sobre o uso do diagnóstico psicológico na escola. 1997. Tese (Doutorado)— Instituto de Psicologia da Universidade de São Paulo, São Paulo, 1997.

ANGELUCCI, C. B. Uma inclusão nada especial: apropriações da política de inclusão de pessoas com necessidades especiais na rede pública de educação fundamental do Estado de São Paulo. 2002. Dissertação (Mestrado) — Instituto de Psicologia da Universidade de São Paulo, São Paulo, 2002.

ARAÚJO, E. A. S. Encaminhamento de crianças para classe especial para deficientes mentais: o olhar e o fazer psicológico. 1997. Dissertação (Mestrado) — Instituto de Psicologia da Universidade de São Paulo, São Paulo, 1997.

DECHICHI, C. Caracterização de crianças encaminhadas à classe especial para deficientes mentais leves. 1993. Dissertação (Mestrado) — Instituto de Psicologia da Universidade de São Paulo, São Paulo, 1993.

FEIJÓ, I. S. C. 0 discurso de psicólogos escolares sobre sua prática: continuidade e ruptura. 2000. Dissertação (Mestrado)— Instituto de Psicologia da Universidade de São Paulo, São Paulo, 2000.

FERREIRA, M. F. C. D. Aspectos da dinâmica intrapsíquica e do desempenho cognitivo em crianças com fracasso escolar. 1998. Dissertação (Mestrado) — Instituto de Psicologia da Universidade de São Paulo, São Paulo, 1998.

FRELLER, C. C. Crianças portadoras de queixa escolar. um enfoque winnicottiano. 1993. Dissertação (Mestrado)— Instituto de Psicologia da Universidade de São Paulo, São Paulo, 1993.

Histórias de indisciplina escolar e a atuação do psicólogo. 2000. Tese (Doutorado) — Instituto de Psicologia da Universidade de São Paulo, São Paulo, 2000.

GUIMARÃES, S. R. K. Dificuldades na aquisição e aperfeiçoamento da leitura e da escrita: o papel da consciência fonológica e da consciência sintática. 2001. Tese (Doutorado) — Instituto de Psicologia da Universidade de São Paulo, São Paulo, 2001.

HOKUMURA, I. H. Estudo psico-social da aprendizagem na relação professor-aluno. 1995. Tese (Doutorado) — Instituto de Psicologia da Universidade de São Paulo, São Paulo, 1995.

JORDÃO, M. C. M. A criança, a deficiência e a escola: uma intervenção orientada pela psicanálise. 2001. Dissertação (Mestrado)— Instituto de Psicologia da Universidade de São Paulo, São Paulo, 2001.

KAJIHARA, 0. T. Avaliação das habilidades fonológicas de disléxicos do desenvolvimento. 1997. Tese (Doutorado)— Instituto de Psicologia da Universidade de São Paulo, São Paulo, 1997. 
KALMUS, J. A produção social da deficiência mental leve. 2000. Dissertação (Mestrado)— Instituto de Psicologia da Universidade de São Paulo, São Paulo, 2000.

KOYAMA, M. A. F. Confrontos no ensino: um estudo psicossocial em situações concretas. 1995. Dissertação (Mestrado)Instituto de Psicologia da Universidade de São Paulo, São Paulo, 1995.

LOUREIRO, M. C. S. Magistério como função pública e compromisso do professor. 1997. Tese (Doutorado)—Instituto de Psicologia da Universidade de São Paulo, São Paulo, 1997.

MACHADO, A. M. Reinventando a avaliação psicológica. 1996. Tese (Doutorado)—Instituto de Psicologia da Universidade de São Paulo, São Paulo, 1996.

MARQUES, M. L. Estudo psicopedagógico da criança pré-silábica resistente dentro de uma intervenção pedagógica construtivistainteracionista. 1993. Dissertação (Mestrado)— Instituto de Psicologia da Universidade de São Paulo, São Paulo, 1993.

MARX, R. B. Análise qualitativa da implantação do construtivismo na rede pública municipal de São Paulo. 1993. Dissertação (Mestrado)— Instituto de Psicologia da Universidade de São Paulo, São Paulo, 1993.

MODELLI, A. Um estudo psicanalítico sobre a escuta dos pais no diagnóstico da dificuldade escolar. 1999. Dissertação (Mestrado)— Instituto de Psicologia da Universidade de São Paulo, São Paulo, 1999.

PAPARELLI, R. Trabalho precoce e escolarização: uma trama complexa. 2001. Dissertação (Mestrado)— Instituto de Psicologia da Universidade de São Paulo, São Paulo, 2001.

PAULA, F. V. Conhecimento metacognitivo de crianças de $3^{a}$ série que apresentam dificuldades na aquisição da leitura. 2001. Dissertação (Mestrado) — Instituto de Psicologia da Universidade de São Paulo, São Paulo, 2001.

PAULO, M. S. L. L. A influência dos aspectos emocionais nos distúrbios de aprendizagem escolar. 1998. Dissertação (Mestrado)— Instituto de Psicologia da Universidade de São Paulo, São Paulo, 1998.

PEREIRA, M. P. A influência da pré-escola na aprendizagem da leitura e da escrita e sua relação com algumas variáveis psicomotoras em crianças da $1^{a}$ série do $1^{\circ}$ grau. 1997. Dissertação (Mestrado) — Instituto de Psicologia da Universidade de São Paulo, São Paulo, 1997.

PEROSA, G. S. Formação docente e fracasso escolar. um estudo sobre a oferta de cursos de capacitação (1983-1994). 1997. Dissertação (Mestrado) — Instituto de Psicologia da Universidade de São Paulo, São Paulo, 1997.

RIBEIRO, M. P. O. Funcionamento cognitivo de crianças com queixas de aprendizagem: jogando e aprendendo a jogar. 2001. Tese (Doutorado)— Instituto de Psicologia da Universidade de São Paulo, São Paulo, 2001.

ROCCO E COSTA, E. L. Análise neuropsicológica da escrita em cadernos escolares. 1992. Tese (Doutorado)— Instituto de Psicologia da Universidade de São Paulo, São Paulo, 1992.

RODRIGUES, O. M. P. R. Desempenho de entrada e aprendizagem de leitura: em busca de relação. 1995. Tese (Doutorado)— Instituto de Psicologia da Universidade de São Paulo, São Paulo, 1995.

ROSA, I. S. Criança e linguagem escrita: teoria e prática da alfabetização numa perspectiva psicogenética. 1991. Dissertação (Mestrado)— Instituto de Psicologia da Universidade de São Paulo, São Paulo, 1981.

ROSE, T. M. S. Compreensão de leitura: ensino e conhecimento. 1995. Tese (Doutorado)— Instituto de Psicologia da Universidade de São Paulo, São Paulo, 1995.

SAWAYA, S. M. A leitura e a escrita como práticas culturais e o fracasso escolar das crianças de classes populares: uma contribuição crítica. 1999. Tese (Doutorado) — Instituto de Psicologia da Universidade de São Paulo, São Paulo, 1999.

SAWAYA, S. M. Pobreza e linguagem oral: as crianças do Jardim Piratininga. 1992. Dissertação (Mestrado)— Instituto de Psicologia da Universidade de São Paulo, São Paulo, 1992. 
SCICCHITANO R. M. J. Alfabetização escolar e fracasso: uma perspectiva construtivista-interacionista. 1991. Tese (Doutorado)— Instituto de Psicologia da Universidade de São Paulo, São Paulo, 1991.

SILVEIRA, F. B. Procedimentos para desenvolver consciência fonológica e ensinar correspondências grafo-fonêmicas em educandos com e sem distúrbios de fala. 2001. Dissertação (Mestrado)— Instituto de Psicologia da Universidade de São Paulo, São Paulo, 2001.

SIQUEIRA, L. F. L. Representações de professores sobre o desempenho escolar: um estudo na cidade de Porto Velho - RO. 2000. Dissertação (Mestrado) — Instituto de Psicologia da Universidade de São Paulo, São Paulo, 2000.

SOUZA, A. M. L. Avaliação no cotidiano da sala de aula da primeira série do ensino fundamental: um estudo etnográfico. 2000. Dissertação (Mestrado) — Instituto de Psicologia da Universidade de São Paulo, São Paulo, 2000.

Entrevista familiar diagnóstica como instrumento auxiliar no estudo da influência dos psicodinamismos da família em crianças com inibição intelectual. 1993. Tese (Doutorado)— Instituto de Psicologia da Universidade de São Paulo, São Paulo, 1993.

SOUZA, D. T. R. Conquistando o espaço escolar. a estruturação do trabalho pedagógico numa classe do ciclo básico. 1991. Dissertação (Mestrado) — Instituto de Psicologia da Universidade de São Paulo, São Paulo, 1991.

TAMBORIL, M. I. B. Aproveitamento escolar no ensino fundamental de Porto Velho -RO, de 1990 a 1997. 2000. Dissertação (Mestrado) — Instituto de Psicologia da Universidade de São Paulo, São Paulo, 2000.

TORRES, M. Z. Processos de desenvolvimento e aprendizagem de adolescentes em oficinas de jogos. 2001. Tese (Doutorado)— Instituto de Psicologia da Universidade de São Paulo, São Paulo, 2001.

VIÉGAS, L. S. Progressão Continuada e suas repercussões na escola pública paulista: concepções dos educadores. 2002. Dissertação (Mestrado) — Instituto de Psicologia da Universidade de São Paulo, São Paulo, 2002.

VIEIRA, N. P. Indo mais rápido: para onde? Um estudo do Projeto Classes de Aceleração da Secretaria de Estado da Educação de São Paulo. 2002. Dissertação (Mestrado)— Instituto de Psicologia da Universidade de São Paulo, São Paulo, 2002.

ZAIDAN, E. Desenvolvimento de uma bateria de testes de triagem da função auditiva central em pré-escolares e escolares na faixa de 6 a 11 anos. 2001. Dissertação (Mestrado) — Instituto de Psicologia da Universidade de São Paulo, São Paulo, 2001.

Recebido em 26.03.04

Aprovado em 27.04.04

Carla Biancha Angelucci é psicóloga, doutoranda em Psicologia Social e mestre em Psicologia Escolar pelo Ipusp, docente em cursos de graduação e pós-graduação lato sensu. bianchaangelucci@ig.com.br

Jaqueline Kalmus é psicóloga, mestre em Psicologia Escolar pelo Ipusp, docente em cursos de graduação e pósgraduação lato sensu. jkalmus@usp.br

Renata Paparelli é psicóloga, doutoranda e mestre em Psicologia Escolar pelo Ipusp, especialista em Saúde do Trabalhador pelo Cerest/SP, docente em cursos de graduação da PUC/SP. rpaparel@uol.com.br

Maria Helena Souza Patto é psicóloga e professora titular do IPUSP. 